\title{
Familial pulmonary valve stenosis, atrial septal defect, and unique electrocardiogram abnormalities
}

\author{
ALLEN A CIUFFO, EMMITT CUNNINGHAM, AND THOMAS A TRAILL \\ From the Division of Cardiology, Department of Medicine, Johns Hopkins Hospital, Baltimore, Maryland \\ 21205, USA.
}

SUMMARY The familial association of pulmonary stenosis, atrial septal defect, and unique electrocardiographic abnormalities involving a mother and two children is reported. Familial pulmonary stenosis not occurring as part of a named syndrome or without associated multiple congenital abnormalities is rare. The constellation of pulmonary stenosis, atrial septal defect, and the particular electrocardiogram abnormalities present here is to our knowledge previously unreported. The pattern of inheritance is consistent with an autosomal dominant mode of transmission.

Inheritance of congenital heart defects is unusual. ${ }^{1}$ Most cases occur in the context of familial syndromes in which cardiac abnormalities are but one manifestation of a disorder involving several systems. ${ }^{2}$ Although pulmonary valve stenosis is a relatively common form of congenital heart disease, its hereditary occurrence is largely limited, like other forms of congenital heart disease, to named syndromes such as Noonan, LEOPARD, and others which are associated with several cardiac and non-cardiac abnormalities. ${ }^{2-5}$ Isolated hereditary pulmonary valve stenosis, in contrast, is rare, ${ }^{3}$ with only three published reports. ${ }^{6-8}$

We report a family in which pulmonary valve stenosis occurred in a mother and two children, and was associated with atrial septal defect and a unique electrocardiographic abnormality, but no extracardiac abnormalities.

\section{Case reports}

CASE 1

The mother, a 62 year old white woman, was known to have had a heart murmur since puberty. She was asymptomatic as a child and tolerated four pregnancies well. One of her pregnancies resulted in a miscarriage at 4.5 months' gestation. The remaining three were premature. Two of her children had congenital heart disease (see below). There was no maternal or paternal history of congenital heart disease, nor a history of heart disease in any of her eight sisters. One year before admission she developed dyspnoea on exertion and cyanosis. Physical examination revealed a well developed white woman with central and peripheral cyanosis. The facies was normal and there were no stigmata of the Noonan syndrome or other generalised genetic disorders. There was a right ventricular impulse and a loud pulmonary ejection click introducing a $4 / 6$ holosystolic murmur. The second heart sound was widely split and fixed. The electrocardiogram (figure) was remarkable for a superior axis $\left(-88^{\circ}\right)$ and the absence of anterior forces in the praecordial leads. Slight cardiomegaly and normal pulmonary vasculature were noted on chest $x$-ray. Two dimensional echocardiography revealed right ventricular hypertrophy with reversed septal movement, a secundum atrial septal defect (ASD), and a thickened, mobile pulmonary valve doming during systole. A pulmonary valve gradient of $90 \mathrm{mmHg}$ and an ASD with a right to left shunt were confirmed at cardiac catheterisation (table). She underwent successful balloon valvuloplasty with reduction of the pulmonary valve gradient to $40 \mathrm{mmHg}$, reversal of the shunt, and an increase in arterial haemoglobin saturation from $75 \%$ to $90 \%$. She was discharged asymptomatic and has done well at four months follow up.

CASE 2

This patient was born three months prematurely. At 6 weeks physical examination revealed a murmur of pulmonary stenosis. The electrocardiogram was similar to his mother's. Marked right ventricular hypertension, a pulmonary valve gradient of 115 


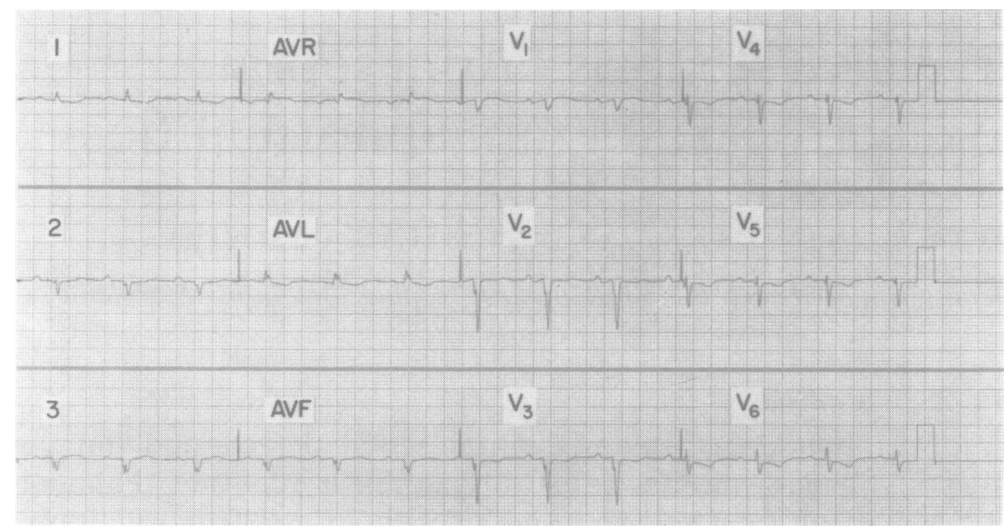

FIGURE Twelvelead electrocardiogram from case 1 . Note the superior axis and the lack of positive forces across the anterior praecordium.

TABLE Right heart catheterisation data from mother and two children with pulmonary stenosis.

\begin{tabular}{|c|c|c|c|c|}
\hline & & $\begin{array}{l}\text { Mother } \\
(\mathrm{mmHg})\end{array}$ & $\begin{array}{l}\text { Son } \\
(m m / H)\end{array}$ & $\begin{array}{l}\text { laughter } \\
\left(\mathrm{mm} \mathrm{Hg}_{\mathrm{g}}\right)\end{array}$ \\
\hline Right atrium & $\begin{array}{l}\text { A wave } \\
V \text { wave } \\
\text { Mean }\end{array}$ & $\begin{array}{l}6 \\
2 \\
4\end{array}$ & $\begin{array}{l}7 \\
2 \\
1\end{array}$ & $\begin{array}{l}6 \\
2 \\
4\end{array}$ \\
\hline Right ventricle & $\begin{array}{l}\text { Systolic } \\
\text { Diastolic }\end{array}$ & $\begin{array}{r}100 \\
8\end{array}$ & $\begin{array}{r}1.30 \\
10\end{array}$ & $\begin{array}{r}115 \\
0\end{array}$ \\
\hline
\end{tabular}

$\mathrm{mmHg}$, and an ASD were confirmed at cardiac catheterisation (table). He underwent corrective cardiac surgery at 13 years of age when valvular pulmonary stenosis and a $2 \times 3 \mathrm{~cm}$ secundum ASD were repaired. He is well 23 years later except for occasional atrial tachyarrhythmias.

\section{CASE 3}

This child was born one month prematurely. As an infant she was noted to have the same murmur as her mother and brother. The electrocardiogram, again similar to her mother's, showed abnormal $\mathrm{R}$ wave progression in the praecordial leads. Cardiac catheterisation at the age of 11 years revealed a pulmonary valve gradient of $94 \mathrm{mmHg}$ (table). Although the diagnosis of ASD was not made in this case, a widely split, fixed second heart sound consistent with an ASD was noted on physical examination. She underwent surgical transpulmonary valvuloplasty and has done well at 17 years follow up.

None of these three affected subjects had any evidence of additional associated congenital abnormalities, such as neck webbing, dystocia canthorum, or skeletal deformities. There was no history of congenital heart disease in other family members, nor any history of consanguinity.

\section{Discussion}

While the majority of congenital heart disease is not inherited, ${ }^{1}$ the existence of genetic factors predisposing to cardiac malformations is evident by the small but identifiable risk, estimated at $2 \%$, to children of parents with congenital heart disease. With the exception of idiopathic hypertrophic subaortic stenosis, however, inheritance of specific cardiac defects is almost exclusively confined to named syndromes in which heart malformations are associated with a recognisable group of non-cardiac abnormalities. Pulmonary valvular stenosis is a prominent feature in two such syndromes, the Noonan syndrome and LEOPARD syndrome. N Although pulmonary valvular stenosis is present in $N$ up to $10.5 \%$ of all patients with congenital heart $\mathcal{N}$ disease, the familial occurrence of pulmonary valve $\omega$ stenosis other than in these two syndromes is rare. ${ }^{2}$ ? In an analysis of familial patterns of congenital $\stackrel{\circ}{c}$ cardiac malformations no cases of heart disease $\stackrel{\mathbb{D}}{\rightarrow}$ were found in 21 subsequent sibs of 20 probands ? with isolated pulmonary valve stenosis. ${ }^{5}$

We have found only three previous published reports of familial pulmonary stenosis. In one $\stackrel{\odot}{\mathbb{Q}}$ kindred three infants were affected and each had $\stackrel{\square}{\square}$ associated multiple congenital abnormalities, in- 
cluding a hypoplastic right ventricle, abnormal facies, and mental and motor retardation." In another, four subjects were affected in three generations; however, in only two patients was the diagnosis confirmed by cardiac catheterisation. One patient had an atrial septal defect. but none had the associated electrocardiogram abnormalities found in the present family. ${ }^{7}$ The third report included a grandfather with pulmonary stenosis and a grandson with pulmonary atresia: however, neither patient had the associated ASD or electrocardiogram abnormalities present in our kindred. ${ }^{.}$

In addition to severe pulmonary valve obstruction and ASD, all three of the affected members in the present family had similar electrocardiogram abnormalities of a type quite unexpected in pulmonary valve stenosis. The electrical axis in the frontal plane was directed superiorly, and in the praecordial leads there was absence of anterior and right forces. resembling the pattern seen in extensive anterior and septal myocardial infarction. Although specific electrocardiographic patterns mav be inherited as part of a recognised disorder, for example in muscular dystrophy, long QT syndrome, or Noonan syndrome, these have invariably represented a manifestation of a recognisable pathological process. In our index case, echocardiography and cineventriculography showed normal left ventricular wall thickness and function with no evidence of regional abnormalities in timing or amplitude of contraction. The basis for these electrocardiographic abnormalities therefore remains obscure.
Although there are only three cases in the present kindred, our patients have such a distinctive grouping of pulmonary valve stenosis, electrocardiographic abnormality, and atrial septal defect that we are forced to infer a genetic aetiology. Although the mode of inheritance cannot be proven in such a small kindred, the pattern is consistent with an autosomal dominant mode.

\section{References}

1 Campbell $M$. Incidence of cardiate malformations at birth and later. and nconatal mortality. Br Heart $J$ 1973:35:189-200).

- Sanchez (ascos A. Genetics of pulmonary stenosis. Acta Cardiol 1972:27:316-30.

Mckeown T. MacMathon T. Parsons CG. The familial incidence of congenital malformations of the heart. Br Heart $J$ $1953: 15: 27,3-7$

t Scuance H. Manc-Garzon F. Kolski R. Cardio-cutancous syndrome (the LEOPARD syndrome). Review of the literature and a new famils. (lin (Genet 1976:9:266-76.

- Caralis D. (har F. Graber JD. Voigt GC. Delincation of multiple cardiac anomalies associated with the Noonan syndrome in an adult and review of the literature. Johns Hopkins Med J 1974:134:346-55.

"Klinge T. I.aursen HB. Familial pulmonary stenosis with under-developed or normal right ventricke. Br Heart J 1975:37:601-4

David TJ. A family with congenital pulmonary valve stenosis. Humangenetik 1974:21:287-8.

"Robinson JC: Hull HB. Rappaport WJ. Pulmonary valvular obstruction in grandfather and grandson. $N$ Engl $J$ Med 1965:273:6811-3.

Correspondence and requests for reprints to $\mathrm{Dr}$ Allen A Ciuffo, Division of Cardiology, Johns Hopkins Hospital, $600 \mathrm{~N}$ Wolfe Street, Baltimore, Maryland 21205, USA. 